\title{
Real-World National Colonoscopy Volume in Korea: A Nationwide Population- Based Study over 12 Years
}

\author{
Jae Myung Cha ${ }^{1}$, Min Seob Kwak ${ }^{1}$, Hyun-Soo Kim², Su Young Kim², Sohee Park ${ }^{3}$, Geun U Park ${ }^{4}$, Jung Kuk Lee ${ }^{5}$, Soo \\ Jin Kim ${ }^{6}$, Hun Hee Lee ${ }^{6}$, Joo Sung Kim ${ }^{7}$, and Won Ho Kim ${ }^{8}$, for the Big Data Research Group of the Korean Society of \\ Gastroenterology
}

${ }^{I}$ Department of Internal Medicine, Kyung Hee University School of Medicine, Seoul, ${ }^{2}$ Department of Internal Medicine, Yonsei University Wonju College of Medicine, Wonju, ${ }^{3}$ Department of Biostatistics, Graduate School of Public Health, Yonsei University, ${ }^{4}$ Department of Biostatics and Computing, Yonsei University, Seoul, ${ }^{5}$ Department of Biostatistics, Yonsei University Wonju College of Medicine, Wonju, ${ }^{6}$ Department of Biostatistics, Kyung Hee University Hospital at Gangdong, ' Department of Internal Medicine, Seoul National University School of Medicine, and ${ }^{8}$ Department of Internal Medicine, Yonsei University College of Medicine, Seoul, Korea

Background/Aims: Little is known about the national colonoscopy volume in Asian countries. This study aimed to assess the national colonoscopy volume in Korea over a 12year period on the basis of a nationwide population-based database. Methods: We conducted a population-based study for colonoscopy claims $(14,511,158$ colonoscopies performed on 13,219,781 patients) on the basis of the Korean National Health Insurance Service database from 2002 to 2013. The 12-year national colonoscopy burden was analyzed according to patient age, patient sex, and healthcare facility type. Results: The overall volume of colonoscopy increased 8-fold over the 12-year period. The annual colonoscopic polypectomy rate significantly increased in all patient sex and age groups over the 12 -years period (all $p<0.001$ ). The yearly colonoscopic polypectomy rate for men was significantly increased compared with that for women $(2.3 \%$ vs $1.7 \%, p<0.001)$ and for the screening-age group compared with that for the young-age group ( $2.0 \%$ vs $1.6 \%, p<0.001)$. The yearly colonoscopic polypectomy rate relative to the total colonoscopy volume significantly increased in primary, secondary, and tertiary facilities by $2.4 \%, 1.9 \%$, and $1.4 \%$ during the 12-year period (all $p<0.001$ ). In addition, the annual colonoscopy volume covered by high-volume facilities significantly increased by $1.8 \%$ in primary healthcare facilities over the 12-year period ( $p<0.001)$. Conclusions: Healthcare resources should be prioritized to allow adequate colonoscopic capacity, especially for men, individuals in the screeningage group, and at primary healthcare facilities. Cost-effective strategies to improve the quality of colonoscopy may focus on primary healthcare facilities and high-volume facilities in Korea. (Gut Liver 2020;14:338-346)

Key Words: Big data; Colonoscopy; Polypectomy; Population

\section{INTRODUCTION}

Colorectal cancer (CRC) is a significant public health problem, as its incidence has been increasing worldwide. ${ }^{1,2}$ Colonoscopy is very effective to reduce the risk of CRC, as most CRCs develop from colorectal adenoma through the adenoma-carcinoma sequence. $^{3-5}$ CRC screening rate has been steadily increasing over the years, which significantly prevents the development of CRC. ${ }^{6}$ As a national CRC screening program, most countries, including Korea, use fecal occult blood tests, whereas several Western countries use colonoscopy. ${ }^{6,7}$ The national CRC screening program in Korea coexists alongside opportunistic colonoscopy screening of persons with an average risk of CRC. ${ }^{8}$

In Western countries, limited resources for colonoscopy have been an obstacle in expanding CRC screening program, because only certain specialists are trained to perform colonoscopy and colonoscopic polypectomy. ${ }^{9-12}$ The estimated colonoscopy capacity was sufficient to screen $80 \%$ of the eligible U.S. population with fecal test, colonoscopy, or a mix of tests in $2014 .{ }^{9}$ Survey study conducted in the United Kingdom reported that $50 \%$ of the endoscopy units provided an adequate colonoscopy service. ${ }^{12}$ In some Asian countries such as Korea, Japan, and China, however, colonoscopy burden may be different from that of Western countries because of the excellent accessibility of

Correspondence to: Hyun-Soo Kim

Department of Internal Medicine, Yonsei University Wonju College of Medicine, 20 Ilsan-ro, Wonju 26426, Korea

Tel: +82-33-741-0505, Fax: +82-33-747-3538, E-mail: hyskim@yonsei.ac.kr

Received on March 22, 2019. Revised on May 25, 2019. Accepted on June 7, 2019. Published online September $19,2019$. pISSN 1976-2283 eISSN 2005-1212 https://doi.org/10.5009/gnl19108

(c) This is an Open Access article distributed under the terms of the Creative Commons Attribution Non-Commercial License (http://creativecommons.org/licenses/by-nc/4.0) which permits unrestricted non-commercial use, distribution, and reproduction in any medium, provided the original work is properly cited. 
colonoscopy, low cost of colonoscopy, and many available experienced colonoscopists. ${ }^{13}$ Currently, however, no populationbased studies have reported the national burden of colonoscopy in Asian countries. A better understanding of national colonoscopy burden may be the first step toward successful implementation of CRC screening program as well as identification of deficits in the current colonoscopy resources in Asian countries.

In this context, we aimed to assess the national burden of colonoscopy according to age, sex, and healthcare facility type, based on a nationwide population-based database in Korea.

\section{MATERIALS AND METHODS}

\section{Data source and study population}

This study is a retrospective nationwide population-based study using the Korean National Health Insurance Service (NHIS) database, which contains all inpatient and outpatient data nationwide since 1989 in Korea. The NHIS database provides a comprehensive healthcare coverage for all Koreans and contains information on claims billed by physicians for services, admissions, diagnoses, procedures, discharge status, and patient demographics. ${ }^{14,15}$ Procedure codes in physician claims databases had a very high level of agreement with data in medical charts. $^{15}$

We identified all persons who had at least one colonoscopy in the NHIS physician billing claims database between January 2002, and December 2013. Longitudinal time change in the national burden of colonoscopy was assessed according to age, sex, and healthcare facility type in 12 years. We determined whether patients had undergone colonoscopy without polypectomy (E7660) or with polypectomy (Q7701, single polypectomy;
Q7702, two or more polypectomies; Q7703, endoscopic mucosal resection) using NHIS codes. In this study, colonoscopic polypectomy included endoscopic mucosal resection (Q7703) but endoscopic submucosal dissection was excluded because this procedure is rarely performed and not reimbursed by NHIS Colonoscopic procedures were analyzed per procedure, as some patients had multiple colonoscopic procedures, whereas an early repeat colonoscopy within 12 months was analyzed per patient.

Study variables were time (2002 to 2013), colonoscopy with or without polypectomy, age groups (young age, $<50$ years; screening age, 50 to 74 years; and elderly age, $\geq 75$ years), sex, healthcare facility type (primary, secondary, tertiary, and others) and annual volume of facility (high-volume or not). Age group classification was based on the current guidelines that recommend CRC screening for 50- to 75-year-old adults at an average risk for CRC. ${ }^{45}$ Primary facility includes a primary outpatient clinic, secondary facility includes a hospital and a general hospital, and tertiary facility includes a specialized general hospital on referral from primary and secondary healthcare facility. Other facility includes dental hospital, nursing hospital, public hospital, and oriental hospital/clinic (traditional medicine hospital/clinics prescribing herbal drug or practicing acupuncture) A high-volume facility was defined as a facility with an annua colonoscopy volume more than 200 cases, because the minimum volume of annual colonoscopy to maintain competency for colonoscopy was 200 cases per year and other universa definition is not available. ${ }^{16,17}$ As a unique situation in Korea, primary healthcare facility includes profit health promotion centers which account for most of high-volume center. As the information used in this study was related only to pseudonyms, the requirement of informed consent was waived. This study

Table 1. National Colonoscopy Burden over the 12-Year Period in Korea

\begin{tabular}{|c|c|c|c|c|}
\hline Year & Total volume & $\begin{array}{l}\text { Colonoscopy without } \\
\text { polypectomy* }\end{array}$ & Colonoscopic polypectomy* & In-patient polypectomy \\
\hline 2002 & 264,345 & 240,167 (90.8) & $24,178(9.1)$ & 9,523 (39.4) \\
\hline 2003 & 448,051 & 408,397 (91.1) & 39,654 (8.9) & $16,016(40.4)$ \\
\hline 2004 & 546,190 & $487,466(89.2)$ & $58,724(10.8)$ & 23,367 (39.8) \\
\hline 2005 & 751,535 & $657,790(87.5)$ & 93,745 (12.5) & $35,033(37.4)$ \\
\hline 2006 & 957,534 & $812,859(84.9)$ & $144,675(15.1)$ & $45,369(31.4)$ \\
\hline 2007 & $1,080,359$ & $892,151(82.6)$ & $188,208(17.4)$ & $54,583(29.0)$ \\
\hline 2008 & $1,207,613$ & $968,661(80.2)$ & $238,952(19.8)$ & 61,273 (25.6) \\
\hline 2009 & $1,441,564$ & $1,136,222(78.8)$ & $305,342(21.2)$ & $75,095(24.6)$ \\
\hline 2010 & $1,601,688$ & $1,226,376(76.6)$ & $375,312(23.4)$ & 84,706 (22.6) \\
\hline 2011 & $1,975,279$ & $1,467,324(74.3)$ & $507,955(25.7)$ & $96,464(19.0)$ \\
\hline 2012 & $2,138,150$ & $1,542,315(72.1)$ & $595,835(27.9)$ & $103,647(17.4)$ \\
\hline 2013 & $2,098,850$ & $1,474,064(70.2)$ & $624,786(29.8)$ & $105,374(16.9)$ \\
\hline \multicolumn{2}{|c|}{ Percent change } & -2.0 & +2.0 & -2.4 \\
\hline
\end{tabular}

Data are presented as number or number (\%).

*The percent is the proportion of procedures performed each year relative to the total colonoscopy volume. 
was approved by the Institutional Review Board of Kyung Hee University Hospital at Gangdong, Seoul, Republic of Korea (IRB number: KHNMC 2018-08-021).

\section{Statistical analysis}

Descriptive analysis was performed on the entire population during the study period. A generalized linear regression model was applied for sex, age group, and healthcare facility type using the annual proportion of colonoscopy/polypectomy among the total volume of colonoscopy at each year, compared with those in 2002 as a reference. The trends in the annual colonoscopic polypectomy burden in each age group were assessed by subtraction using the chi-square distribution. All statistical tests were two-sided, and a p-value $<0.05$ was considered statistically significant. All statistical analyses were conducted using SAS 9.4 statistical software (SAS institute Inc., Cary, NC, USA) and R software packages R version 3.5.1 (R Foundation for Statistical Computing, Vienna, Austria; https://www.R-project.org).

Table 2. National Colonoscopy Burden According to Sex over the 12-Year Period in Korea

\begin{tabular}{|c|c|c|c|c|c|c|}
\hline \multirow[b]{2}{*}{ Year } & \multicolumn{3}{|c|}{ Men } & \multicolumn{3}{|c|}{ Women } \\
\hline & Total volume & $\begin{array}{l}\text { Colonoscopy without } \\
\text { polypectomy* }\end{array}$ & Polypectomy* & Total volume & $\begin{array}{l}\text { Colonoscopy without } \\
\text { polypectomy* }\end{array}$ & Polypectomy* \\
\hline 2002 & 144,252 & $127,678(88.5)$ & $16,574(11.5)$ & 120,093 & 112,489 (93.7) & $7,604(6.3)$ \\
\hline 2003 & 241,827 & $214,526(88.7)$ & 27,301 (11.3) & 206,224 & 193,871 (94.0) & $12,353(6.0)$ \\
\hline 2004 & 293,264 & 252,753 (86.2) & $40,511(13.8)$ & 252,926 & 234,713 (92.8) & $18,213(7.2)$ \\
\hline 2005 & 408,158 & $344,383(84.4)$ & 63,775 (15.6) & 343,377 & 313,407 (91.3) & 29,970 (8.7) \\
\hline 2006 & 523,894 & $426,143(81.3)$ & 97,751 (18.7) & 433,640 & $386,716(89.2)$ & $46,924(10.8)$ \\
\hline 2007 & 600,398 & 472,939 (78.8) & $127,459(21.2)$ & 479,961 & 419,212 (87.3) & 60,749 (12.7) \\
\hline 2008 & 666,918 & 507,257 (76.1) & 159,661 (23.9) & 540,695 & $461,404(85.3)$ & 79,291 (14.7) \\
\hline 2009 & 792,350 & $590,410(74.5)$ & $201,940(25.5)$ & 649,214 & $545,812(84.1)$ & $103,402(15.9)$ \\
\hline 2010 & 882,390 & 634,393 (71.9) & 247,997 (28.1) & 719,298 & $591,983(82.3)$ & 127,315 (17.7) \\
\hline 2011 & $1,115,603$ & $776,992(69.6)$ & $338,611(30.4)$ & 859,676 & $690,332(80.3)$ & $169,344(19.7)$ \\
\hline 2012 & $1,198,330$ & $804,831(67.2)$ & $393,499(32.8)$ & 939,820 & $737,484(78.5)$ & $202,336(21.5)$ \\
\hline 2013 & $1,166,880$ & $761,413(65.3)$ & $405,467(34.7)$ & 931,970 & $712,651(76.5)$ & $219,319(23.5)$ \\
\hline \multicolumn{2}{|c|}{ Percent change } & -2.3 & +2.3 & & -1.7 & +1.7 \\
\hline
\end{tabular}

Data are presented as number or number (\%).

*The percent is the proportion of procedures performed each year relative to the total colonoscopy volume.

Table 3. National Colonoscopy Burden According to Age Group over the 12-Year Period in Korea

\begin{tabular}{|c|c|c|c|c|c|c|c|c|c|}
\hline \multirow{2}{*}{ Year } & \multicolumn{3}{|c|}{ Young age (<50 yr) } & \multicolumn{3}{|c|}{ Screening age (50-74 yr) } & \multicolumn{3}{|c|}{ Elderly age ( $\geq 75$ yr) } \\
\hline & $\begin{array}{c}\text { Total } \\
\text { volume }\end{array}$ & $\begin{array}{l}\text { CS without } \\
\text { polypectomy }\end{array}$ & Polypectomy & $\begin{array}{c}\text { Total } \\
\text { volume }\end{array}$ & $\begin{array}{l}\text { CS without } \\
\text { polypectomy* }\end{array}$ & Polypectomy* & $\begin{array}{c}\text { Total } \\
\text { volume }\end{array}$ & $\begin{array}{l}\text { CS without } \\
\text { polypectomy* }\end{array}$ & Polypectomy* \\
\hline 2002 & 131,431 & $124,226(94.5)$ & 7,205 (5.5) & 125,060 & 109,097 (87.2) & 15,963 (12.8) & 7,854 & $6,844(87.1)$ & $1,010(12.9)$ \\
\hline 2003 & 229,271 & 217,796 (95.0) & $11,475(5.0)$ & 206,768 & 180,233 (87.2) & 26,535 (12.8) & 12,012 & $10,368(86.3)$ & $1,644(13.7)$ \\
\hline 2004 & 267,815 & 251,194 (93.8) & $16,621(6.2)$ & 262,325 & 222,634 (84.9) & $39,691(15.1)$ & 16,050 & $13,638(85.0)$ & $2,412(15.0)$ \\
\hline 2005 & 361,729 & 335,013 (92.6) & $26,716(7.4)$ & 367,829 & 304,638 (82.8) & $63,191(17.2)$ & 21,977 & $18,139(82.5)$ & $3,838(17.5)$ \\
\hline 2006 & 442,551 & 401,190 (90.7) & 41,361 (9.3) & 483,284 & 386,253 (79.9) & $97,031(20.1)$ & 31,699 & $25,416(80.2)$ & 6,283 (19.8) \\
\hline 2007 & 479,373 & $425,120(88.7)$ & $54,253(11.3)$ & 563,229 & 437,513 (77.7) & $125,716(22.3)$ & 37,757 & 29,518 (78.2) & $8,239(21.8)$ \\
\hline 2008 & 508,168 & $439,933(86.6)$ & 68,235 (13.4) & 654,693 & 494,628 (75.6) & $160,065(24.4)$ & 44,752 & $34,100(76.2)$ & 10,652 (23.8) \\
\hline 2009 & 578,202 & $494,490(85.5)$ & $83,712(14.5)$ & 807,666 & $600,228(74.3)$ & 207,438 (25.7) & 55,696 & $41,504(74.5)$ & $14,192(25.5)$ \\
\hline 2011 & 709,141 & $577,893(81.5)$ & $131,248(18.5)$ & $1,186,855$ & $834,456(70.3)$ & $352,399(29.7)$ & 79,283 & $54,975(69.3)$ & $24,308(30.7)$ \\
\hline 2012 & 691,351 & 552,549 (79.9) & $138,802(20.1)$ & $1,351,311$ & $926,350(68.6)$ & $424,961(31.4)$ & 95,488 & $63,416(66.4)$ & 32,072 (33.6) \\
\hline 2013 & 649,927 & $507,664(78.1)$ & 142,263 (21.9) & $1,340,951$ & 896,796 (66.9) & 444,155 (33.1) & 107,972 & $69,604(64.5)$ & $38,368(35.5)$ \\
\hline \multicolumn{2}{|c|}{ Percent change } & -1.6 & +1.6 & & -2.0 & +2.0 & & -2.1 & +2.1 \\
\hline
\end{tabular}

Data are presented as number or number (\%).

*The percent is the proportion of procedures performed each year relative to the total colonoscopy (CS) volume. 


\section{RESULTS}

\section{National burden of colonoscopy}

Table 1 shows the longitudinal time change in the national colonoscopy burden for 12 years, based on 14,511,158 colonoscopies on 13,219,781 patients. Compared with the total volume of colonoscopy in 2002, the total volume of colonoscopy doubled within 2 years in 2004, quadrupled within 5 years in 2007, hextupled within 8 years in 2010, and octupled within 10 years in 2012. The annual proportion of polypectomy performed at each year among the total volume of colonoscopy significantly increased by $+2.0 \%$ from 2002 to 2013 ( $p<0.001$ ). However, inpatient polypectomy rate per year significantly decreased by
$-2.4 \%(\mathrm{p}<0.001)$.

\section{National burden of colonoscopy according to sex and age group}

The overall colonoscopy burden was higher in men than women with ratio of 1.2 to 1 (Table 2). Compared with the volume of polypectomy in 2002, the proportion of polypectomy among the total volume of colonoscopy per year was significantly increased for both sexes in 12 years (both $\mathrm{p}<0.001$ ). For sex difference, the proportion of polypectomy performed at each year among the total volume of colonoscopy was significantly increased in men than in women $(2.3 \%$ vs $1.7 \%, \mathrm{p}<0.001)$.

The burden of total colonoscopy in young age, screening age,

Table 4. National Colonoscopy Burden According to Healthcare Facility Type over the 12-Year Period in Korea

\begin{tabular}{|c|c|c|c|c|c|c|c|c|}
\hline \multirow{2}{*}{ Year } & \multicolumn{4}{|c|}{ Primary healthcare facility } & \multicolumn{4}{|c|}{ Secondary healthcare facility } \\
\hline & $\begin{array}{l}\text { Total } \\
\text { facility }\end{array}$ & $\begin{array}{c}\text { Total } \\
\text { CS volume }\end{array}$ & $\begin{array}{l}\text { CS without } \\
\text { polypectomy* }\end{array}$ & Polypectomy & $\begin{array}{l}\text { Total } \\
\text { facility }\end{array}$ & $\begin{array}{c}\text { Total } \\
\text { CS volume }\end{array}$ & $\begin{array}{l}\text { CS without } \\
\text { polypectomy* }\end{array}$ & Polypectomy \\
\hline 2002 & 741 & 97,302 & 89,447 (91.9) & $7,855(8.1)$ & 213 & 89,074 & $80,322(90.2)$ & $8,752(9.8)$ \\
\hline 2003 & 941 & 173,580 & $161,535(93.1)$ & $12,045(6.9)$ & 307 & 172,338 & $155,935(90.5)$ & $16,403(9.5)$ \\
\hline 2004 & 1,118 & 208,541 & $188,736(90.5)$ & $19,805(9.5)$ & 454 & 225,861 & 200,916 (89.0) & 24,945 (11.0) \\
\hline 2005 & 1,281 & 286,832 & 252,915 (88.2) & 33,917 (11.8) & 571 & 328,030 & $286,629(87.4)$ & $41,401(12.6)$ \\
\hline 2006 & 1,508 & 367,715 & $312,673(85.0)$ & $55,042(15.0)$ & 660 & 425,631 & $361,774(85.0)$ & 63,857 (15.0) \\
\hline 2007 & 1,635 & 420,900 & $346,348(82.3)$ & $74,552(17.7)$ & 717 & 481,575 & $397,277(82.5)$ & $84,298(17.5)$ \\
\hline 2008 & 1,791 & 479,126 & $380,046(79.3)$ & $99,080(20.7)$ & 809 & 538,892 & 433,290 (80.4) & $105,602(19.6)$ \\
\hline 2009 & 1,894 & 584,781 & $452,727(77.4)$ & $132,054(22.6)$ & 856 & 627,587 & 499,776 (79.6) & $127,811(20.4)$ \\
\hline 2010 & 2,040 & 664,000 & 497,557 (74.9) & $166,443(25.1)$ & 908 & 696,670 & $539,123(77.4)$ & $157,547(22.6)$ \\
\hline 2011 & 2,221 & 862,130 & $627,247(72.8)$ & $234,883(27.2)$ & 950 & 857,009 & $642,009(74.9)$ & $215,000(25.1)$ \\
\hline 2012 & 2,316 & 938,075 & $661,358(70.5)$ & $276,717(29.5)$ & 992 & 923,782 & $671,683(72.7)$ & 252,099 (27.3) \\
\hline 2013 & 2,408 & 918,035 & $626,622(68.3)$ & 291,413 (31.7) & 1,020 & 916,029 & $648,732(70.8)$ & $267,297(29.2)$ \\
\hline \multicolumn{2}{|c|}{ Percent change } & & -2.4 & +2.4 & & & -1.9 & +1.9 \\
\hline \multirow[b]{2}{*}{ Year } & \multicolumn{4}{|c|}{ Tertiary healthcare facility } & \multicolumn{4}{|c|}{ Other healthcare facility } \\
\hline & $\begin{array}{l}\text { Total } \\
\text { facility }\end{array}$ & $\begin{array}{c}\text { Total } \\
\text { CS volume }\end{array}$ & $\begin{array}{l}\text { CS without } \\
\text { polypectomy* }\end{array}$ & Polypectomy & $\begin{array}{l}\text { Total } \\
\text { facility }\end{array}$ & $\begin{array}{c}\text { Total } \\
\text { CS volume }\end{array}$ & $\begin{array}{l}\text { CS without } \\
\text { polypectomy* }\end{array}$ & Polypectomy \\
\hline 2002 & 41 & 77,969 & 70,398 (90.3) & $7,571(9.7)$ & 0 & 0 & $0(0.0)$ & $0(0.0)$ \\
\hline 2003 & 42 & 102,126 & 90,921 (89.0) & $11,205(11.0)$ & 1 & 7 & $6(85.7)$ & $1(14.3)$ \\
\hline 2004 & 43 & 111,648 & $97,691(87.5)$ & $13,957(12.5)$ & 5 & 140 & 123 (87.9) & $17(12.1)$ \\
\hline 2005 & 41 & 136,467 & $118,046(86.5)$ & $18,421(13.5)$ & 14 & 206 & 200 (97.1) & $6(2.9)$ \\
\hline 2006 & 43 & 163,608 & $137,889(84.3)$ & $25,719(15.7)$ & 18 & 580 & $523(90.2)$ & $57(9.8)$ \\
\hline 2007 & 45 & 176,816 & $147,695(83.5)$ & $29,121(16.5)$ & 28 & 1,068 & 831 (77.8) & 237 (22.2) \\
\hline 2008 & 48 & 188,401 & $154,408(82.0)$ & 33,993 (18.0) & 53 & 1,194 & 917 (76.8) & 277 (23.2) \\
\hline 2009 & 44 & 227,388 & $182,176(80.1)$ & $45,212(19.9)$ & 69 & 1,808 & $1,543(85.3)$ & 265 (14.7) \\
\hline 2010 & 44 & 238,498 & 187,558 (78.6) & $50,940(21.4)$ & 84 & 2,520 & 2,138 (84.8) & $382(15.2)$ \\
\hline 2011 & 45 & 252,192 & 194,992 (77.3) & $57,200(22.7)$ & 97 & 3,948 & $3,076(77.9)$ & $872(22.1)$ \\
\hline 2012 & 47 & 269,869 & $204,870(75.9)$ & $64,999(24.1)$ & 127 & 6,424 & 4,404 (68.6) & $2,020(31.4)$ \\
\hline 2013 & 45 & 259,116 & $194,901(75.2)$ & 64,215 (24.8) & 136 & 5,670 & 3,809 (67.2) & $1,861(32.8)$ \\
\hline \multicolumn{3}{|c|}{ Percent change } & -1.4 & +1.4 & & & & \\
\hline
\end{tabular}

Data are presented as number or number (\%).

*The percent is the proportion of procedures performed each year relative to the total colonoscopy (CS) volume. 
and elderly age groups was 38.8\%, 57.2\%, and 4.0\%, respectively (Table 3). Compared with the volume of polypectomy in 2002, the proportion of polypectomy among the total volume of colonoscopy per year was significantly increased for all age groups in 12 years (all $\mathrm{p}<0.001$ ). For age group difference, the proportion of polypectomy among the total volume of colonoscopy per year significantly increased in the screening and elderly age groups compared with the young age group $(2.0 \%$ and $2.1 \%$ vs $1.6 \%$, both $\mathrm{p}<0.001)$.

\section{National burden of colonoscopy according to healthcare facility type}

Our analysis was focused on primary, secondary, and tertiary facilities, as the colonoscopy volume in other facility type was only $0.2 \%$ (Table 4). The number of facilities claimed that colonoscopy procedures increased by 3.2 -fold and 4.8 -fold in primary and secondary facilities in 12 years. In total, 41.3\%, $43.3 \%$, and $15.2 \%$ of polypectomies were performed in primary, secondary, and tertiary facilities for 12 years. Compared with the colonoscopy database in 2002, the proportion of polypectomy among the total volume of colonoscopy per year significantly increased in primary, secondary, and tertiary facilities by $2.4 \%, 1.9 \%$, and 1.4\%, respectively (all $\mathrm{p}<0.001$ ). The annual polypectomy rate of each facility type among total polypectomies was significantly increased only in the primary facilities $(\mathrm{p}<0.001)$, but, significantly decreased in the tertiary facilities $(p<0.001)$ and not changed in the secondary facilities $(p=0.274)$ (Fig. 1).

\section{Colonoscopy burden by high-volume facility}

Compared to that in the 2002 database, the number of highvolume facility significantly increased by $2.8 \%$ and by $2.0 \%$ in primary and secondary facilities (both $\mathrm{p}<0.001$ ), but was not changed in the tertiary facilities $(p>0.1)$ (Table 5). The annual colonoscopy volume covered by a high-volume facility among the total volume of colonoscopy significantly increased in primary and secondary facilities by $1.8 \%$ and by $0.4 \%$ per year (both $\mathrm{p}<0.001$ ), but it was not changed in the tertiary facilities in 12 years $(p=0.196)$.

\section{Early repeat colonoscopy within 12 months}

Overall, $8.4 \%$ of $13,219,781$ persons had an early repeat colonoscopy, and $3.3 \%$ of 10,922,565 persons had an early repeat colonoscopy without polypectomy by per-patient analysis (Supplementary Table 1). The proportion of an early repeat colonoscopy without polypectomy among the total volume of colonoscopy significantly decreased in 12 years (by $0.3 \%$ for two colonoscopies and by $0.1 \%$ for $\geq 3$ colonoscopies) (both $\mathrm{p}<0.001)$.

\section{DISCUSSION}

This population-based study is the first Asian study that investigated the national colonoscopy volume according to age sex, and healthcare facility type. The national colonoscopy volume has progressively increased in all sex, age groups, and healthcare facility types in the 12 years. The volume of colonoscopic polypectomy significantly increased in men than in women and in the screening age group than in the young age group. These findings are predictable because old age and male sex are well-known risk factors for colorectal neoplasia. ${ }^{18,19}$ The colonoscopic polypectomy volume significantly increased in the primary facility than the secondary and tertiary facility. A steep rise in the volume of colonoscopy by the primary healthcare facilities may be explained by the introduction of the "National CRC Screening Program" in 2004 in Korea. ${ }^{8}$ In Canada, similarly, the proportion of colonoscopies performed in the nonhospital setting increased with the introduction of the "ColonCancerCheck" program: $18.9 \%$ increase from 2000 to $2007^{20}$ and $35.1 \%$ increase from 2013 to $2014 .^{21}$ Higher rates of the polypectomy in the primary healthcare facilities may be explained by that diminutive polyps may be removed by polypectomy, not by biopsy forceps, as well as that non-adenomatous polyps on the distal colon may be removed by polypectomy in primary healthcare facilities. Our findings may indicate that healthcare resources should be prioritized such that there is adequate colonoscopic capacity, especially for men, screening age group, and primary healthcare facilities.

We could estimate the capacity of screening colonoscopy at the population level on the basis of our data. In 2012, 15,537,702 Koreans were invited to undergo CRC screening and 3,884,839 (25.0\%) of them underwent CRC screening

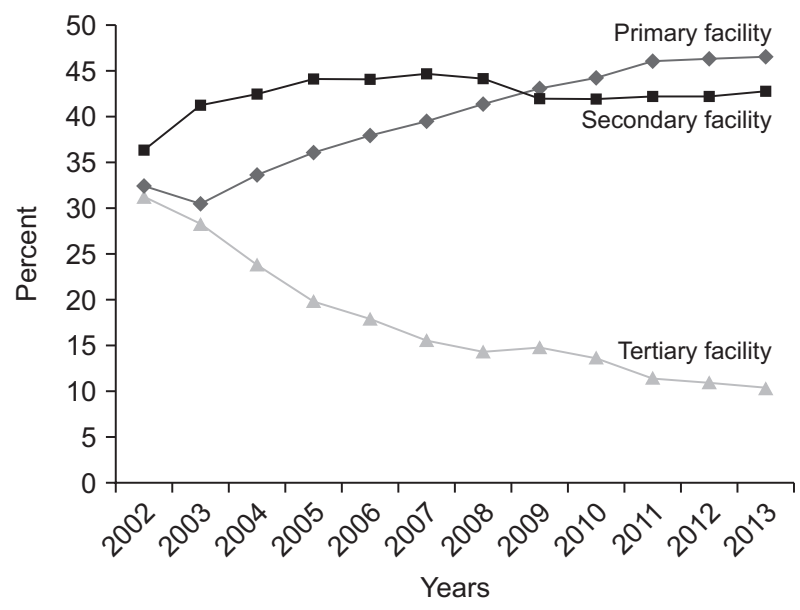

Fig. 1. Annual colonoscopic polypectomy volume in each type of healthcare facility. The proportion of colonoscopic polypectomies performed relative to the total polypectomy volume significantly increased by $1.6 \%$ in primary facilities and decreased by $1.8 \%$ in tertiary facilities (both $\mathrm{p}<0.001$ ) compared with the rates in the 2002 database. 


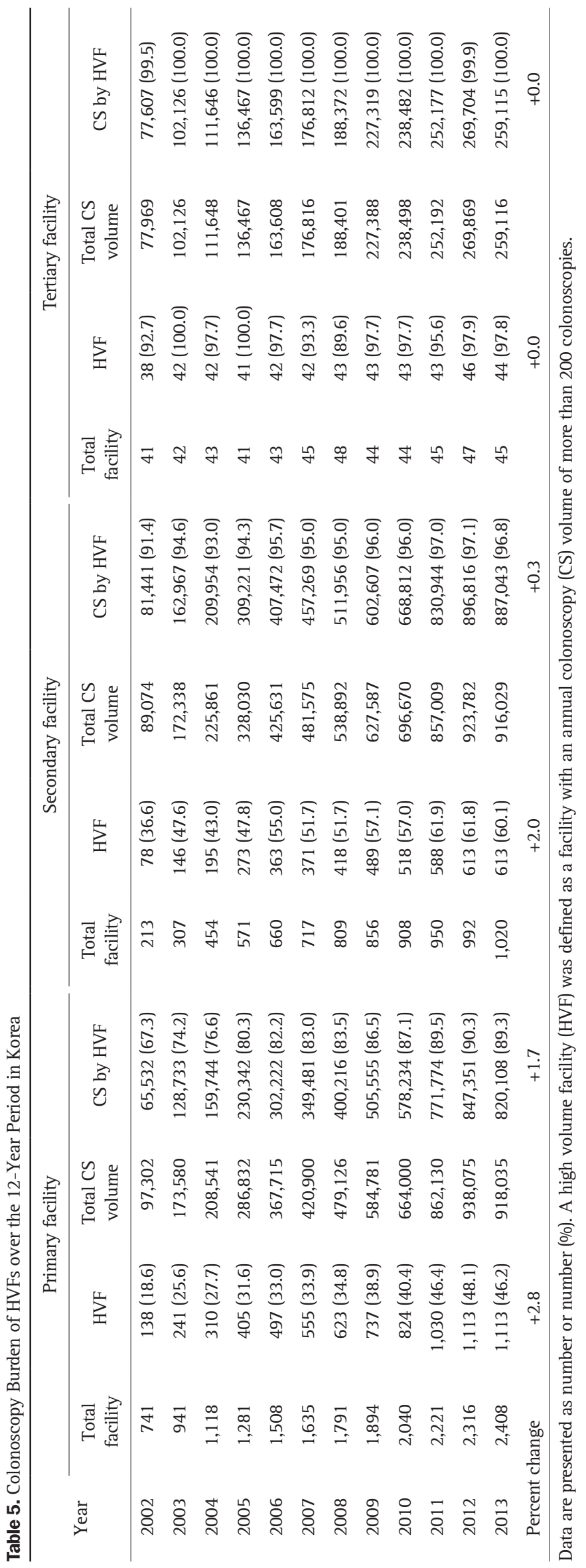


with the "National CRC Screening Program." ${ }^{8}$ One-third of the colonoscopic capacity may be used for CRC screening, because screening indication was about one-third of the total colonoscopy. ${ }^{22}$ Theoretically, if the 3,884,839 persons are eligible for CRC screening and one-third (i.e., 699,617) of the total volume of colonoscopy of 2012 are provided, 5.6 years may be required to screen the potential population of CRC screening in 2012. Therefore, 5- to 10-year interval of screening colonoscopy may cover all eligible CRC screening population in Korea. However, the potential capacity of screening colonoscopy at the population level may consider the growing rate of the target population, participation rate of screening program, screening interval, cost-effectiveness, and safety and quality of colonoscopy screening.

In previous studies, the quality of colonoscopy was suboptimal in primary healthcare facilities..$^{20,21,23-25}$ In a populationbased study from Ontario, ${ }^{20}$ the odds ratio of early repeat colonoscopy $\leq 5$ years after a negative complete colonoscopy was 1.26 when the index colonoscopy had been performed in a nonhospital setting. Similarly, the adjusted odds ratio for an early repeat colonoscopy $\leq 6$ months was 1.41 when baseline colonoscopy was performed at a nonhospital facility compared with a teaching or community hospital. ${ }^{21}$ The early repeat colonoscopy at a nonhospital facility may be explained by their suboptimal baseline colonoscopy. In addition, direct access colonoscopy of primary facility had lower detection rate of large $(\geq 10 \mathrm{~mm})$ polyp and lower completion rate of colonoscopy than conventional colonoscopy group. ${ }^{23}$ An important variation in colonoscopy quality among outpatient facilities was suggested by significant variation in the unplanned hospital visits within 7 days of colonoscopy. ${ }^{24}$ In a retrospective study from Florida, ${ }^{25}$ a higher risk of adverse events was associated with colonoscopies performed in ambulatory surgery centers (odds ratio, 1.27; 95\% confidence interval, 1.16 to 1.40 ). Considering the predominantly increasing colonoscopy volume in primary healthcare facilities, the colonoscopy quality improvement program may be reinforced in primary healthcare facilities.

We also investigated the volume of an early repeat colonoscopy within 12 months. The volume of an early repeat colonoscopy without polypectomy among the total volume of colonoscopy decreased by $0.3 \%$ for two colonoscopies and by $0.1 \%$ for $\geq 3$ colonoscopies from 2002 to 2013. In Canada, 2.4\% of 334,663 persons had an early repeat colonoscopy within 6 months. ${ }^{21}$ In the Veterans Health Administration data, ${ }^{26}$ colonoscopy was used more frequently than the recommended intervals on guidelines by $16 \%$ of patients without adenoma. In addition, $46.2 \%$ of the Medicare population underwent a repeated examination within 7 years and $23.5 \%$ of patients had no clear indication for the early repeat examination. ${ }^{27}$ In our study, the number of high-volume facility significantly increased in primary and secondary facilities, and the annual colonoscopy volume covered by the high-volume facilities also increased regardless of facility types. For example, only 11.7\% of colonoscopy volume in primary facilities and 3.2\% of colonoscopy volume in secondary facilities was performed in low-volume facilities in 2013. Therefore, the cost-effective strategy to increase colonoscopy quality may be focused on high-volume facilities in Korea.

The use of a NHIS enabled us to perform the largest study to date that assessed the national volume of colonoscopy, and the results are virtually free from referral bias and readily generalizable owing to the population-based design. However, some limitations should be considered. We concede that one of the limitations of our study is secondary data with the uncertainty regarding the accuracy of the diagnosis. However, previous studies with NHIS as data sources have generally shown that procedures and diagnoses are coded accurately. ${ }^{14,15}$ As no specific details of the colonoscopy were recorded in the NHIS, safety, quality, and the cost of colonoscopy were not addressed in this study. In addition, we cannot assess detailed clinical information for the cause of an early repeat colonoscopy within 12 months. We defined high-volume facility (i.e., annual colonoscopy volume $\geq 200$ ) based on some evidence, ${ }^{16,17}$ but it may still be arbitrary as it was a criterion for an endoscopist, not a healthcare facility. In a German screening colonoscopy registry, the detection rate of any neoplasm was better for annual colonoscopy volume $\geq 200$ than annual colonoscopy volume $<50$ (27.5\% vs 21.9\%, p<0.001). ${ }^{16}$ Spanish Society of Gastrointestinal Endoscopy also recommended at least 200 annual screening colonoscopies to maintain colonoscopy quality in CRC screening. ${ }^{17}$

In conclusion, the national volume of colonoscopy has been progressively increasing regardless of sex, age group, and healthcare facility types for the past 12 years in Korea. Healthcare resources should be prioritized such that there is adequate colonoscopic capacity, especially for men, subjects of screening age, and primary healthcare facilities. Considering difference in colonoscopy quality among facilities and majority of colonoscopy volume covered by high-volume facility, cost-effective strategy to improve colonoscopy quality may be focused on primary healthcare facilities and high-volume facilities in Korea.

\section{CONFLICTS OF INTEREST}

No potential conflict of interest relevant to this article was reported.

\section{ACKNOWLEDGEMENTS}

This study was supported by grants from the Korean Society of Gastroenterology, the National R\&D Program for Cancer Control (HA17C0046 and 1720230) and the Korean National Health Clinical Research (NHCR) project (HC16C2320), Ministry of Health and Welfare, Republic of Korea. 
Data source: National Health Information Database (NHIS2018-4-062) made by the National Health Insurance Service (NHIS) was used.

\section{AUTHOR CONTRIBUTIONS}

Study concept and design, analysis, and interpretation of data, drafting of the manuscript, critical revision of the manuscript for important intellectual content: J.M.C., H.S.K. Data management, statistical analysis: M.S.K., G.U.P., S.P., J.K.L., S.Y.K., S.J.K., H.H.L. Acquisition of data, administrative, and technical support of this study: J.S.K., W.H.K. Study supervision: J.M.C., H.S.K., J.S.K., W.H.K.

\section{ORCID}

Jae Myung Cha Min Seob Kwak Hyun-Soo Kim Su Young Kim Sohee Park Geun U Park Jung Kuk Lee Soo Jin Kim Hun Hee Lee Joo Sung Kim Won Ho Kim
https://orcid.org/0000-0001-9403-230X https://orcid.org/0000-0002-8988-7423 https://orcid.org/0000-0001-7190-0362 https://orcid.org/0000-0002-6486-8445 https://orcid.org/0000-0001-8513-5163 https://orcid.org/0000-0002-8594-4611 https://orcid.org/0000-0003-1874-449X https://orcid.org/0000-0002-1676-8060 https://orcid.org/0000-0002-4493-509X https://orcid.org/0000-0001-6835-4735 https://orcid.org/0000-0002-5682-9972

\section{REFERENCES}

1. Siegel RL, Miller KD, Fedewa SA, et al. Colorectal cancer statistics, 2017. CA Cancer J Clin 2017;67:177-193.

2. Shin A, Jung KW, Woo H, Jeong SY. Colorectal cancer incidence in Korea is not the highest in the world. Cancer Res Treat 2016;48:864-867.

3. Levin B, Lieberman DA, McFarland B, et al. Screening and surveillance for the early detection of colorectal cancer and adenomatous polyps, 2008: a joint guideline from the American Cancer Society, the US Multi-Society Task Force on Colorectal Cancer, and the American College of Radiology. Gastroenterology 2008;134:15701595.

4. Rex DK, Boland CR, Dominitz JA, et al. Colorectal cancer screening: recommendations for physicians and patients from the U.S. Multi-Society Task Force on colorectal cancer. Am J Gastroenterol 2017;112:1016-1030.

5. Arditi C, Peytremann-Bridevaux I, Burnand B, et al. Appropriateness of colonoscopy in Europe (EPAGE II). Screening for colorectal cancer. Endoscopy 2009;41:200-208.

6. Schreuders EH, Ruco A, Rabeneck L, et al. Colorectal cancer screening: a global overview of existing programmes. Gut 2015;64:1637-1649.

7. Vleugels JL, van Lanschot MC, Dekker E. Colorectal cancer screening by colonoscopy: putting it into perspective. Dig Endosc 2016;28:250-259.

8. Suh M, Song S, Cho HN, et al. Trends in participation rates for the National Cancer Screening Program in Korea, 2002-2012. Cancer Res Treat 2017;49:798-806.

9. Joseph DA, Meester RG, Zauber AG, et al. Colorectal cancer screening: estimated future colonoscopy need and current volume and capacity. Cancer 2016;122:2479-2486.

10. Levin TR. Colonoscopy capacity: can we build it? Will they come? Gastroenterology 2004;127:1841-1844.

11. Brown ML, Klabunde CN, Mysliwiec P. Current capacity for endoscopic colorectal cancer screening in the United States: data from the National Cancer Institute Survey of Colorectal Cancer Screening Practices. Am J Med 2003;115:129-133.

12. Macfarlane B, Leicester R, Romaya C, Epstein O. Colonoscopy services in the United Kingdom. Endoscopy 1999;31:409-411.

13. Choi JH, Cha JM, Yoon JY, Kwak MS, Jeon JW, Shin HP. The current capacity and quality of colonoscopy in Korea. Intest Res 2019;17:119-126.

14. Cheol Seong S, Kim YY, Khang YH, et al. Data resource profile: the National Health Information Database of the National Health Insurance Service in South Korea. Int J Epidemiol 2017;46:799800.

15. Cha JM, Kim HS, Kwak MS, et al. Features of postcolonoscopy colorectal cancer and survival times of patients in Korea. Clin Gastroenterol Hepatol 2019;17:786-788.

16. Zwink N, Stock C, Birkner B, Hoffmeister M, Brenner H. Screening colonoscopy volume and detection of colorectal neoplasms: a state-wide study from Bavaria, Germany. Eur J Cancer Prev 2017;26:181-188.

17. Jover R, Herráiz M, Alarcón 0 , et al. Clinical practice guidelines: quality of colonoscopy in colorectal cancer screening. Endoscopy 2012;44:444-451.

18. Strum WB. Colorectal adenomas. N Engl J Med 2016;374:10651075.

19. Kolligs FT, Crispin A, Munte A, Wagner A, Mansmann U, Göke B. Risk of advanced colorectal neoplasia according to age and gender. PLoS One 2011;6:e20076.

20. Hol L, Sutradhar R, Gu S, et al. Repeat colonoscopy after a colonoscopy with a negative result in Ontario: a population-based cohort study. CMAJ Open 2015;3:E244-E250.

21. Paszat L, Sutradhar R, Baxter NN, Tinmouth J, Rabeneck L. Repeat colonoscopy within 6 months after initial outpatient colonoscopy in Ontario: a population-based cross-sectional study. Can J Gastroenterol Hepatol 2017;2017:5917057.

22. Audibert C, Perlaky A, Glass D. Global perspective on colonoscopy use for colorectal cancer screening: a multi-country survey of practicing colonoscopists. Contemp Clin Trials Commun 2017;7:116-121.

23. Ahmed J, Mehmood S, Khan SA, Rao MM. Direct access colonoscopy in primary care: is it a safe and practical approach? Scott Med J 2013;58:168-172. 
346 Gut and Liver, Vol. 14, No.3, May 2020

24. Ranasinghe I, Parzynski CS, Searfoss R, et al. Differences in colonoscopy quality among facilities: development of a postcolonoscopy risk-standardized rate of unplanned hospital visits. Gastroenterology 2016;150:103-113.

25. Chukmaitov A, Bradley CJ, Dahman B, Siangphoe U, Warren JL, Klabunde CN. Association of polypectomy techniques, endoscopist volume, and facility type with colonoscopy complications. Gastrointest Endosc 2013;77:436-446.
26. Murphy CC, Sandler RS, Grubber JM, Johnson MR, Fisher DA. Underuse and overuse of colonoscopy for repeat screening and surveillance in the Veterans Health Administration. Clin Gastroenterol Hepatol 2016;14:436-444.

27. Goodwin JS, Singh A, Reddy N, Riall TS, Kuo YF. Overuse of screening colonoscopy in the Medicare population. Arch Intern Med 2011;171:1335-1343. 